\title{
Ascertainment of children with congenital cataract through the National Congenital Anomaly System in England and Wales
}

\author{
Jugnoo S Rahi, Beverley Botting, and The British Congenital Cataract Interest Group*
}

\begin{abstract}
Backgroundlaims-Congenital ocular anomalies contribute significantly to childhood visual morbidity, with congenital cataract being a major cause of visual impairment throughout the world. As in many other countries, a National Congenital Anomaly System (NCAS) exists in England and Wales to monitor the frequency of ocular and other anomalies in order to identify new public health hazards and inform aetiological research. The aim of this study was to assess level of ascertainment by the NCAS of children with congenital cataract.

Methods-Using independent ophthalmic and paediatric national active surveillance schemes, all infants ( $\leqslant 1$ year) newly diagnosed with congenital and infantile cataract in England and Wales in 1 year from September 1995 were identified. These notifications were compared with those made independently to the NCAS during the same period. The proportion of cases identified by the active surveillance schemes and also notified to the NCAS was determined.
\end{abstract}

Results-10\% (15/149) of eligible children with newly diagnosed congenital or infantile cataract were actually notified to the NCAS. A higher proportion of those diagnosed as neonates $(16 \%, 14 / 85)$ than in later infancy $(2 \%, 1 / 64)$ was ascertained through the NCAS. There is a need for better verification of notifications and reported information in the NCAS.

Conclusion-Currently, ascertainment of congenital cataract through the NCAS is low and the system is likely to be insensitive to small but important changes in risk factors for this disorder. This limits its use for monitoring secular and other trends in ocular anomalies. Strategies to improve its future use are discussed, including enhancing the awareness and participation of ophthalmic professionals involved in managing children with anomalies. (Br f Ophthalmol 2001;85:1049-1051)

Congenital anomalies contribute significantly to childhood mortality and morbidity, ${ }^{12}$ with ocular anomalies being a major cause of visual impairment throughout the world. ${ }^{34}$ In England and Wales congenital cataract alone accounted for $3 \%$ of all new blindness or partial sight certifications among children in
1990 , with other ocular or central nervous system anomalies accounting for a further $19 \% .^{5}$

In many industrialised countries, monitoring systems and registers have been established, at national and regional levels, to routinely monitor the frequency of all congenital anomalies, in order to inform service planning, identify new public heath hazards, and inform aetiological research. The National Congenital Anomaly System (NCAS) in England and Wales is run by the Office for National Statistics (ONS). ${ }^{2}$ It was established in 1964 following the epidemic of malformations in children born to mothers treated with thalidomide during pregnancy ${ }^{2}$ and served initially as a rapid surveillance system. It has become the main routine national source for estimating the frequency of all congenital anomalies in children. Reporting of affected children is voluntary and passive. Reported anomalies are categorised using the World Health Organization (WHO) International Classification of Diseases (ICD) system ${ }^{6}$ and underlying aetiology is not reported separately. Minimum identifying information is collected on notified cases and currently there is no routine verification of notifications or of reported data.

Despite being the main source for estimation of birth prevalence of congenital ocular anomalies, the proportion of eligible children actually notified to the NCAS has not been specifically evaluated at national level. We have determined the level of ascertainment by this system of children newly diagnosed with congenital cataract in England and Wales in the context of a population based active surveillance study of this disorder, conducted independently to determine its incidence, ${ }^{6 \mathrm{a}}$ mode of detection, ${ }^{7}$ and causes. ${ }^{8}$

\section{Methods}

All children with congenital or infantile cataract in the United Kingdom, newly diagnosed during the 12 month period from October 1995, were identified prospectively through two independent national active surveillance schemes comprising ophthalmologists and paediatricians, respectively, to ensure a good level of ascertainment of eligible cases. ${ }^{7}$ This reflected the delivery of screening and treatment services for this disorder in the UK, to which there is universal, cost free access through the National Health Service. Ophthalmologists undertake treatment while paediatricians are responsible for universal routine ocular examinations of newborn infants undertaken to detect cataract as well as for the management of any underlying or associated 
systemic disorders. ${ }^{9}$ The ophthalmic surveillance scheme was established for this study, through the British Congenital Cataract Interest Group, following a national survey of practice. ${ }^{10}$ The long established paediatric scheme, run by the British Paediatric Surveillance Unit of the Royal College of Paediatrics and Child Health, has successfully facilitated incidence studies of a number of uncommon childhood conditions. ${ }^{11}$ For the duration of the study, paediatricians were sent reporting cards monthly, and ophthalmologists every 2 months, with which to notify new cases or to confirm that no new cases had been seen, thus making the notification process active rather than passive. Detailed information was collected about all notified cases using standard forms developed specifically for the study. Data on all reported cases were reviewed by the investigators to confirm eligibility. Capturerecapture analysis indicated that $92 \%$ of eligible infants had been identified through these sources, as reported previously with further details, including the characteristics of cases reported to each surveillance scheme and the extent and nature of overlap between them. ${ }^{10}$

Independently, all ICD-10 $\operatorname{codes}^{6}$ applicable to congenital or infantile cataract, isolated or in conjunction with systemic or other ocular disease, were tabulated. All new notifications to the NCAS in the 2 years between January 1995 and December 1996 which included any of these codes were extracted. Our review of a random sample of previous notifications indicated that children diagnosed outside infancy were unlikely to be notified to the NCAS, despite recent abolishment of the previous upper age limit for notification of 10 days after birth. ${ }^{2}$ Therefore we restricted our search to those aged 12 months or less at notification. To ensure such "late" notifications were identified, a 2 year time frame was used to straddle the 1 year case ascertainment period of the surveillance study. We manually matched those cases identified in England and Wales through the active surveillance schemes described earlier with notifications to the NCAS using initials, sex, date of birth, partial postcode, laterality of cataract and the presence of other anomalies. A successful match required agreement on at least four criteria. This procedure was conducted twice during the course of the study and again at the end of the case ascertainment period. The proportion of cases identified by active surveillance and also notified to the NCAS was determined.

\section{Results}

In 12 months from October 1995, 149 children, born in 1995 or 1996, with congenital cataract diagnosed by their first birthday were identified in England and Wales through the ophthalmic and paediatric surveillance schemes. Of these, $85(57 \%)$ children were diagnosed in the first month of life.

In 2 years from January 1995, there were 21 notifications to the NCAS of congenital cataract in children aged 1 year or less. Three $(14 \%)$, also notified through the paediatric surveillance scheme, were subsequently confirmed by their managing ophthalmologists as not having cataract. One child with multiple anomalies died shortly after birth, precluding further verification, and together with two other cases with insufficient information for matching, had to be excluded. The remaining $15(71 \%)$ children, 14 aged 1 month or less at notification, were matched with cases identified through the ophthalmic and paediatric surveillance schemes.

Thus, $10 \%$ (15/149) of eligible children with newly diagnosed congenital or infantile cataract were actually notified to the NCAS. A higher proportion of those diagnosed as neonates $(16 \%, 14 / 85)$ than in later infancy $(2 \%, 1 / 64)$ was ascertained through the NCAS. Given the very small number of cases notified to the NCAS, analysis by factors that might influence notification, such as laterality of cataract, geographic region, or associated systemic disease, was considered inappropriate, being subject to a high level of random error.

\section{Discussion}

Present ascertainment of children with congenital and infantile cataract through passive reporting to the National Congenital Anomaly System is low. There also appears to be a need for routine verification of both notifications and reported information. Currently, the NCAS is likely to be insensitive to small but important changes in risk factors for congenital cataract and large changes in frequency are likely to be detected with limited precision. This restricts its use in monitoring secular and other trends of this, and possibly other, ocular anomalies.

Completeness of reporting to the NCAS varies with the nature and severity of the anomaly, some severe, life threatening anomalies being better ascertained, ${ }^{12-16}$ as well as with the presence of multiple malformations. ${ }^{17}$ Thus, better ascertainment might be expected of ocular anomalies, such as anophthalmia, that may be more readily diagnosed than cataract, but nevertheless it is unlikely to be high. ${ }^{16}{ }^{18}$ Indeed, from the NCAS the combined birth prevalence of all ocular anomalies, at 1 per 10000 total births ${ }^{19}$ is one sixth of that reported by the European Registration of Congenital Anomalies (EUROCAT) ${ }^{20}$ and similar to the prevalence of anophthalmia and microphthalmia in England reported recently from a disorder specific register. ${ }^{18}$ In contrast with the latter sources, notification to the NCAS is passive and previously has relied mainly on a single source.

In common with other malformation reporting systems elsewhere, underascertainment and inaccuracies in the NCAS have been attributed to aspects of both design and implementation. ${ }^{13}$ Specifically, a major review ${ }^{2}$ of the NCAS undertaken recently advocated that new approaches should be adopted to improve early ascertainment together with further promotion of notification of later diagnosed anomalies. The need for better validation of 
reported data was also emphasised but the difficulties in undertaking this, given the limited information currently recorded about notified cases, are illustrated by the present study. In response to that review, the use of multiple sources, using electronic data transfer from some regional anomaly registers, has been successfully implemented recently in the NCAS. ${ }^{21}$ Adoption of statutory notification, not advocated in the review, might improve ascertainment but would not necessarily guarantee it. We suggest the measures already adopted may be insufficient on their own to improve significantly the ascertainment of ocular anomalies. Their diagnosis requires specialist assessment of affected children by ophthalmic health professionals, many of whom may be unfamiliar with the NCAS. Thus, they may be unaware that they can report newly diagnosed children of any age through three different routes: by informing the NCAS notifier for their local health authority, by directly reporting to their regional anomaly register or by directly contacting the Office for National Statistics who can facilitate notification (ncas@ons.gov.uk). There is a need to enhance the awareness and participation of all ophthalmic professionals involved in the diagnosis and management of children with congenital anomalies. Effective monitoring of anomalies remains important to improving the health of children ${ }^{122}$ : those responsible for the care of affected children remain best placed to strengthen the ability to achieve this.

This article contains material which is Crown copyright and is reproduced with the permission of the Office for National Statistics.

Jugnoo Rahi was supported by a Medical Research Council clinical training fellowship. The study was supported by the British Council for the Prevention of Blindness and Children Nationwide Medical Research Fund.

We are indebted to all clinicians who contributed information, the executive committee of the British Paediatric mation, the executive committee of the British Paediatric
Surveillance Unit for the opportunity to conduct the surveilSurveillance Unit for the opportunity to conduct the surveil-
lance study and the Office for National Statistics for access to lance s

We thank Mr David Taylor and Professor Catherine Peckham for their support of this study and for comments on an earlier draft of this paper.

There is no conflict of interest.

\section{Appendix}

Members of the British Congenital Cataract Interest Group: Mr W Aclimandos, Ms G Adams, Mr S Armstrong, Mr N Astbury, Mr A Assaf, Mr D Banerjee, Miss L Beck, Mr A Beckingsale, Mr G Bedford, Mr L Benjamin, Miss B Billington, Miss T Blamires, Mr P Bloom, Mr J Brazier, Mr D Brosnahan, Professor A Bron, Mr I Brown, Mr R Brown, Mr D Boase, Mr J Bolger, Mr R Bowell, Miss M Boodhoo, Mr J Bradbury, Mr J Bryars, Miss P Burgess, Mr J Burke, Ms L Butler, Mr D Calver, Mr A Casswell, Mr A Chandna, Mr W Church, Mr J Clarke, Mr M Clarke, Mr R Condon, $\mathrm{Mr}$ M Cole, Mr M Dang, Mr S Daya, Mr R Darvell, Dr P D Davies, Mr C Dodd, Mr R Doran, Dr J Dudgeon, Professor G Dutton, Mr R Edwards, Mr A Evans, Mr N Evans, Mr J Elston, Mr H El-Kasaby, Miss B Enoch, Mr ff Fisher, Professor A Fielder, Mr B Fleck, Dr A Gaskell, Miss $M$ Gibbens, $M r$ B Greaves, $M r$ R Gregson, Mr P Gregory, Mr S Haworth, Mr MH Heravi, Mr R Holden, Mr R Humphry, Mr C Hutchinson, Mr J Innes, Dr E Johnson, Mr I K Jalili, Mrs N Kayali,
Mr N C Kaushik, Mr S Kaye, Mr S Kotta, Mr T Lavy, Mr D Laws, Miss J Leitch, Mr C Liu, Mr I C Lloyd, Miss C MacEwen, Mr G Mackintosh, Mr A Mandal, Mr R Markham, Mr G McGinnity, Mr B McCleod, Mr J McConnell, Mr A Moore, Mr A Morrell, Mr R Morris, Dr G Morrice, Mr B Moriarty, Mr A Mushin, Mr C Munton, $\mathrm{Mr} \mathrm{M}$ Neugebauer, $\mathrm{Mr} \mathrm{J}$ Nolan, $\mathrm{Mr} \mathrm{M}$ O'Keefe, Mr G O'Connor, Miss R Ohri, Mr C Peckar, Mr S Perry, Mr R Phillips, Mr N Price, Mr A Quinn, Mr I Quershi, Mr A Rahman, Mr A Rennie, Mr A Ridgway, Mr M Roper-Hall, Mr E Rosen, Miss I Russell Eggitt, Mr A Shun Shin, Dr V Thaller, Mr R Taylor, Mr D Taylor, Mr W Tormey, Mr J Twomey, Mr $\mathrm{S}$ Verghese.

1 Wilcox AJ. The health of our children. Am $\mathcal{f}$ Epidemiol 1999;150:665-6.

2 A working group of the Registrar General's Medical Advisory Committee. The OPCS Monitoring Scheme for Congenital Malformations. Occasional Paper 43. London: OPCS, 1995 .

3 Hornby S, Gilbert CE, Rahi JS, et al. Regional variations in blindness in children due to microphthalmos, anophthalmos and coloboma. Ophthalmic Epidemiol 2000;7:127-38.

4 Foster A, Gilbert C. Epidemiology of visual impairment in children. In:Taylor D, ed. Paediatric ophthalmology. 2nd ed. London: Blackwell Science, 1997:3-12.

5 Evans J. Causes of blindness and partial sight in England and Wales 1990-91. Studies on medical and population subjects No 57. London: HMSO, 1995.

6 World Health Organization. International statistical classification of diseases and health related problems. 10th revision. Geneva:WHO, 1992

6a Rahi JS, Dezateux C, and the British Congenital Cataract Interest Group. Measuring and interpreting the incidence of congenital ocular anomalies: lessons from a national study of congenital cataract in the UK. Invest Ophthalmol Vis Sci 2001;42:1444-8.

7 Rahi JS, Dezateux C, for the British Congenital Cataract Interest Group. National cross-sectional study of detection of congenital and infantile cataract in the United Kingdom:role of screening and surveillance. BMF 1999; 318:362-5.

8 Rahi JS, Dezateux C, for the British Congenital Cataract Interest Group. Congenital and infantile cataract in the United Kingdom: underlying or associated factors. Invest Ophthalmol Vis Sci 2000;41:2108-14.

9 Hall DM. Health for all children. 3rd ed. Report of the Third oint Working Party on Child Health Surveillance. Oxford: Oxford University Press, 1996

10 Rahi JS, Dezateux C, for the British Congenital Cataract Interest Group. Capture-recapture analysis of ascertainment by active surveillance in the British Congenital Cataract Study. Invest Ophthalmol Vis Sci 1999;40:236-9.

11 British Paediatric Surveillance Unit. British paediatric surveillance unit 13th annual report 1999-2000. London: Royal College of Paediatrics and Child Health, 2000.

12 Payne JN. Limitations of the OPCS congenital malformation notification systems illustrated by examination of congenital malformations of the cardiovascular systems in districts within the Trent region. Public Health 1992;106:43748.

13 Knox EG, Armstrong EH, Lancashire R. The quality of notification of congenital malformations. F Epidemiol Community Health 1984;38:296-305.

14 Hey K, O'Donnell M, Murphy M, et al. Use of local neural tube defect registers to interpret national trends. Arch Dis Child 1994;71:F198-202

15 Dutton SJ, Owens JR, Harris F. Ascertainment of congenital malformations: a comparative study of two systems. $\mathcal{F}$ Epidemiol Community Health 1991;45:294-8.

16 Knox EG, Lancashire R. Epidemiology of congenital malformations. London: HMSO, 1991.

17 Calle EE, Khoury MJ. Completeness of the discharge diagnosis as a measure of birth defects recorded in the hospital birth record. Am f Epidemiol 1991;134:69-77.

18 Dolk H, Busby A, Armstrong BG, et al. Geographical variation in anophthalmia and microphthalmia in England, 1988-94. BMF 1998;317:905-10.

19 Office for National Statistics. Congenital anomaly statistics 1995 and 1996. Series MB3 no 11. London: Stationery Office, 1999.

20 EUROCAT Working Group. Surveillance of congenital anomalies 1980-1990. EUROCAT Report 5. Brussels: EUROCAT Working Group, 1993.

21 Botting B. The impact of more complete data from Wales on the National Congenital Anomaly system. Health Statistics Quarterly 2000;5:7-9.

22 Rosano A, Botto LD, Botting B, et al. Infant mortality and congenital anomalies from 1950 to 1994: an international perspective. F Epidemiol Community Health 2000;54:660-6. 